\title{
Prognostic value of cortical magnetic stimulation in spinal cord injury
}

\author{
C E Clarke BSc MD MRCP,${ }^{1} \mathrm{H}$ Modarres-Sadeghi MRCP(I) ${ }^{2} \mathrm{~J}$ A Twomey MD, \\ MRCP, ${ }^{2}$ A A Burt BSc, FRCP ${ }^{1}$
}

\section{Departments of ${ }^{1}$ Neurology and ${ }^{2}$ Neurophysiology, Pinderfields District General Hospital, Aberford Road, Wakefield, West Yorkshire WF1 4DG, England.}

\begin{abstract}
Cortical magnetic stimulation was performed in a consecutive series of 10 patients presenting within 15 days of traumatic spinal cord injury. In those patients with complete paraplegia or quadriplegia, motor evoked potentials at presentation were absent below the level of the lesion. Six months after the injury, potentials had returned in the biceps brachii and abductor pollicis brevis muscles in some quadriplegic cases, but remained absent from the tibialis anterior in all of this group. None of those with a complete lesion made a significant functional recovery. Of the three patients with incomplete quadriplegia, two showed a significant recovery after 6 months. Motor evoked potentials were recordable below the level of the lesion at presentation in these cases, although the latencies were prolonged. In the remaining patient who failed to improve, potentials were unrecordable throughout the study. This small pilot study suggests that cortical magnetic stimulation may be useful in refining the prognosis in patients with an incomplete spinal cord injury.
\end{abstract}

Keywords: spinal cord injury; cortical magnetic stimulation; motor evoked potentials; prognosis.

\section{Introduction}

The prognosis for significant recovery of function following traumatic spinal cord injury (SCI) is poor. At present, the only way of predicting neurological improvement is by clinical examination. Those patients with an incomplete lesion, with some retained motor and/or sensory function below the level of the lesion, have a higher probability of improvement. Thus far, investigative techniques have not been informative in assessing such cases.

In the early 1980s Merton \& Morton ${ }^{1}$ first described the technique of electrical stimulation of the human motor cortex as a way of measuring central motor conduction time $(\mathrm{CMCT})$. This was superseded by cortical magnetic stimulation (CMS) since this method is painless and more easily performed. ${ }^{2,3}$ This procedure has been used to demonstrate abnormal motor conduction in patients with multiple sclerosis, ${ }^{4,5}$ motor

Correspondence: Dr C E Clarke, Department of Neurology, Hull Royal Infirmary, Anlaby Road, Hull HU3 2JZ, England. neuron disease ${ }^{6}$ hereditary spastic paraparesis; ${ }^{7}$ degenerative ataxic disorders, ${ }^{8}$ and cervical spondylosis. ${ }^{9,10}$ Furthermore, absent motor conduction in the acute phase of stroke has been shown to predict a poor outcome at $2^{11}$ and $12^{12}$ months.

The aim of this pilot study was to assess whether cortical magnetic stimulation performed soon after acute spinal cord injury is able to predict the degree of neurological improvement attained by 6 months post injury.

\section{Methods}

\section{Patients}

A consecutive series of 10 patients (nine male and one female) presenting to the Spinal Injuries Unit at Pinderfields Hospital within 15 days of a traumatic spinal cord injury were recruited for the study. The mean age of the group was 29.9 years (range 16-54). Each patient gave informed consent to take part in the study which was approved by the local ethical committee. Patients with a history of epilepsy, cognitive impairment, 
psychiatric disorder, cardiac pacemaker in situ, intracranial or intraspinal metal artefacts, pregnancy or lactation were excluded from the study.

Each patient underwent a standardised clinical and neurophysiological examination as soon as possible after admission and again 6 months following the injury.

\section{Clinical evaluation}

The standardised clinical examination was based on that used in the American National Acute Spinal Cord Injury Study. ${ }^{13}$ Using the MRC 5-point grading scale, power was assessed bilaterally in deltoid, biceps, triceps, flexor carpi radialis, extensor carpi radialis, and abductor pollicis brevis in the upper limbs, and iliopsoas, hip extensors, hamstrings, quadriceps, tibialis anterior, gastrocnemius, and extensor hallucis longus in the lower limbs. Scores from all 26 muscle groups were summated to give an overall motor score (maximum 130).

Pinprick and light touch sensation were tested in the 29 dermatomes from C2 to S5 bilaterally and scored in each as 0 for absent, 1 impaired or 2 normal. The scores were summated to provide overall pain and light touch scores (maximum 116).

Patients were classified as quadriplegic if T1 innervated muscles were weak, with or without weakness in more cephalad myotomes. Paraplegia was defined as weakness caudal to $\mathrm{T} 1$ innervated myotomes. Cord lesions were divided into complete and incomplete categories depending on whether motor and sensory function were totally or partially absent below the level of the lesion.

\section{Technique}

Transcranial magnetic stimulation was performed using a Novametrix Magstim 200 machine (Novametric, Bristol, UK). A circular coil centred flat on the scalp over $\mathrm{Cz}$ (international 10/20 system) was used when targeting abductor pollicis brevis (APB) and biceps brachii (BB) muscles. A figure-of- 8 coil over $\mathrm{Fz}$ was used for recording from tibialis anterior (TA). The coil position had to be altered slightly in each case to achieve optimal excitation. Responses were recorded from surface electrodes using a Dantec Counterpoint machine (Dantec, Wales).

Threshold was established by slowly increasing stimulus strength. Once achieved, the stimulus was then increased by a further $20 \%$ and the latency and amplitude of compound muscle action potentials recorded. Five responses were recorded, each with voluntary activation. The shortest latency together with the highest amplitude response (measured peak to peak) were used for analysis.

Peripheral conduction time to $\mathrm{BB}$ was measured directly following stimulation at Erb's point. In APB and TA, the ' $F$ ' response latencies were utilised and peripheral conduction time was calculated using the formula $(\{\mathrm{f}-1\} / 2)$ as described previously. ${ }^{5.6}$ CMCT was calculated by subtracting the peripheral latency from the cortical latency after transcranial magnetic stimulation. Normal values were established using age-matched controls. For CMCT, the mean plus 2 standard deviations was taken as the upper limit of normal $(\mathrm{BB}=9.5 \mathrm{~ms}$, $\mathrm{APB}=9.2 \mathrm{~ms}, \mathrm{TA}=16.2 \mathrm{~ms})$. For amplitude measurements, the mean minus 2 standard deviations was taken as the lower limit of normal $(\mathrm{BB}=3 \mathrm{mV}, \mathrm{APB}=2 \mathrm{mv}$, $\mathrm{TA}=3 \mathrm{mV}$ ).

\section{Results}

\section{Patients}

The characteristics of the patients are detailed in Table I along with the aetiology of the injury and the radiographic findings. Three paraplegic patients had a complete lesion; no cases of incomplete paraplegia were included in the series. In three quadriplegic patients the lesion was incomplete and in four complete.

\section{Assessment intervals}

The mean delay in performing the initial clinical assessment of 6.2 days (Table II) was largely attributable to late referral of cases to the spinal injuries unit. The patients with a complete quadriplegia were referred within three days, whereas those with a paraplegia or incomplete quadriplegia were referred between 3 and 15 days post injury. 
Table I Patient details and nature of injuries

\begin{tabular}{|c|c|c|c|c|c|c|}
\hline $\begin{array}{l}\text { Patient } \\
\text { number }\end{array}$ & Sex & $\begin{array}{l}\text { Age } \\
\text { (years) }\end{array}$ & Cause of injury & Radiological findings & $\begin{array}{c}\text { Quadriplegic or } \\
\text { paraplegic }(\mathrm{Q} \text { or } \mathrm{P})\end{array}$ & $\begin{array}{c}\text { Complete or incomplete } \\
\text { (C or I) }\end{array}$ \\
\hline 1 & $\mathrm{~F}$ & 31 & RTA & Fracture-dislocation $\mathrm{C} 6 / 7$ & Q & $\mathrm{C}$ \\
\hline 2 & M & 17 & Speedway riding & Crush fracture T12/L1 & $\mathrm{P}$ & $\mathrm{C}$ \\
\hline 3 & M & 24 & RTA & Burst C5 & $\mathrm{Q}$ & I \\
\hline 4 & M & 45 & Handgliding & Fused $\mathrm{C} 2 / 3$ only & Q & $\mathrm{C}$ \\
\hline 5 & M & 54 & RTA & Shattered C5 & Q & $\mathrm{C}$ \\
\hline 6 & M & 24 & Shallow dive & Wedge fracture C5 & $\mathrm{Q}$ & $\mathrm{I}$ \\
\hline 7 & M & 33 & RTA & Fracture-dislocation $\mathrm{T} 2 / 3$ & $\mathrm{P}$ & $\mathrm{C}$ \\
\hline 8 & $\mathbf{M}$ & 16 & RTA & Fracture-dislocation T12/L1 & $\mathrm{P}$ & $\mathrm{C}$ \\
\hline 9 & M & 25 & Gymnastics & Fracture-dislocation $\mathrm{C} 4 / 5$ & Q & $\mathrm{C}$ \\
\hline 10 & M & 30 & RTA & Fracture arch $\mathrm{C} 2$ & Q & I \\
\hline
\end{tabular}

$\mathrm{RTA}=$ road traffic accident

Table II Change in clinical scores

\begin{tabular}{|c|c|c|c|c|c|c|c|c|c|c|c|c|}
\hline \multirow[t]{2}{*}{ Type } & \multirow[t]{2}{*}{$\begin{array}{l}\text { Patient } \\
\text { number }\end{array}$} & \multicolumn{2}{|c|}{$\begin{array}{l}\text { Assessment time } \\
\text { (days from injury) }\end{array}$} & \multicolumn{3}{|c|}{ Motor score } & \multicolumn{3}{|c|}{ Light touch score } & \multicolumn{3}{|c|}{ Pinprick score } \\
\hline & & $1 \mathrm{st}$ & 2nd & 1 st & 2nd & $2 \mathrm{nd}-1 \mathrm{st}$ & $1 \mathrm{st}$ & 2nd & $2 \mathrm{nd}-1 \mathrm{st}$ & $1 \mathrm{st}$ & $2 n d$ & $2 \mathrm{nd}-1 \mathrm{st}$ \\
\hline Paraplegia complete & $\begin{array}{l}2 \\
7 \\
8\end{array}$ & $\begin{array}{r}3 \\
15 \\
13\end{array}$ & $\begin{array}{l}203 \\
202 \\
181\end{array}$ & $\begin{array}{l}60 \\
60 \\
60\end{array}$ & $\begin{array}{l}88 \\
60 \\
60\end{array}$ & $\begin{array}{r}+28 \\
0 \\
0\end{array}$ & $\begin{array}{l}76 \\
36 \\
78\end{array}$ & $\begin{array}{l}84 \\
36 \\
78\end{array}$ & $\begin{array}{r}+8 \\
0 \\
0\end{array}$ & $\begin{array}{l}76 \\
36 \\
78\end{array}$ & $\begin{array}{l}84 \\
36 \\
78\end{array}$ & $\begin{array}{r}+8 \\
0 \\
0\end{array}$ \\
\hline Quadriplegia incomplete & $\begin{array}{r}3 \\
6 \\
10\end{array}$ & $\begin{array}{r}5 \\
12 \\
6\end{array}$ & $\begin{array}{l}188 \\
206 \\
195\end{array}$ & $\begin{array}{l}34 \\
88 \\
53\end{array}$ & $\begin{array}{r}38 \\
116 \\
119\end{array}$ & $\begin{array}{r}+4 \\
+28 \\
+66\end{array}$ & $\begin{array}{r}82 \\
64 \\
116\end{array}$ & $\begin{array}{r}60 \\
114 \\
116\end{array}$ & $\begin{array}{r}-22 \\
+50 \\
0\end{array}$ & $\begin{array}{l}82 \\
64 \\
64\end{array}$ & $\begin{array}{r}60 \\
113 \\
74\end{array}$ & $\begin{array}{l}-22 \\
+49 \\
+10\end{array}$ \\
\hline Quadriplegia complete & $\begin{array}{l}1 \\
4 \\
5 \\
9\end{array}$ & $\begin{array}{l}3 \\
2 \\
1 \\
2\end{array}$ & $\begin{array}{l}275 \\
187 \\
195 \\
197\end{array}$ & $\begin{array}{r}16 \\
0 \\
0 \\
2\end{array}$ & $\begin{array}{r}36 \\
74 \\
17 \\
9\end{array}$ & $\begin{array}{r}+20 \\
+74 \\
+17 \\
+7\end{array}$ & $\begin{array}{l}14 \\
22 \\
16 \\
14\end{array}$ & $\begin{array}{l}24 \\
14 \\
20 \\
14\end{array}$ & $\begin{array}{r}+10 \\
-8 \\
+4 \\
0\end{array}$ & $\begin{array}{l}14 \\
22 \\
16 \\
14\end{array}$ & $\begin{array}{r}24 \\
6 \\
12 \\
14\end{array}$ & $\begin{array}{r}+10 \\
-16 \\
-4 \\
0\end{array}$ \\
\hline
\end{tabular}


The second 6 month clinical assessment was performed after a mean of 203 days.

The initial neurophysiological assessment was performed a mean of 12.4 days after the injury (Table III). The distribution of assessment times was skewed due to one examination 43 days post injury. This patient required ventilatory support within a day of admission, soon after the clinical examination had been done. The second magnetic stimulation was completed a mean of 190 days post injury. The delay compared with the clinical examination was increased by difficulties in arranging the latter in case 1 following discharge.

\section{Paraplegia (complete)}

Clinical improvement occurred only in one patient with such a lesion (patient 2, Table II), but he remained wheelchair bound. Compound muscle action potentials could not be elicited in any of these patients at presentation or at 6 months post injury (Table III). Patient 8 demonstrated abnormal CMCT in APB at both assessments yet power in this muscle was normal throughout.

\section{Quadriplegia (incomplete)}

Significant clinical improvement occurred in patients 6 and 10 who were eventually able to return to their former employment with little residual disability (Table II). CMCT was abnormal below the level of the lesion in each case when first examined, but was clearly demonstrable compared with the other patient in this group (Table III). Although CMCT tended to improve over the course of the study, it only returned to normal in TA in patient 6 and APB in patient 10 .

The other patient in this group did not make a significant improvement, although the severity of the motor lesion soon after injury was greater in this case. CMCT could not be recorded below the level of the lesion in this case throughout the study.

\section{Quadriplegia (complete)}

Patients 1, 5 and 9 suffered a poor outcome from spinal cord injury (Table II). Although patient 4 showed a large increase in motor score by 6 months, this was not translated into an equivalent functional improvement; he continues to use a wheelchair and has little useful upper limb function.

At the first examination, CMCT was absent in all muscle groups in these patients except for biceps in case 1 in whom it became abnormal by the second assessment (Table III). In patient 5, a potential was recordable in biceps by the second test which was associated with an increase in power from grade 3 to 4 . In patient 4 , the better clinical outcome was associated with recordable potentials in biceps and APB by the time of the second assessment.

The amplitude of the compound muscle action potential following magnetic stimulation showed considerable variation, but in general was abnormally low when the latency was increased (Table III). However, it proved to be a less reliable indicator of outcome compared with CMCT.

\section{Discussion}

Using electrical ${ }^{14,15}$ and magnetic ${ }^{16,17}$ stimulation, it has been shown that motor evoked potentials are abnormal several months to years after traumatic SCI. To our knowledge, the only study to examine the prognostic value of central motor conduction time in the acute phase of SCI was that of Tegenthoff. ${ }^{18}$ Although data on all patients are not presented, it is stated that 'the recovery of lost motor evoked potentials in a few patients preceded the favourable clinical outcome'. It is difficult to draw firm conclusions from the present pilot study but valuable pointers can be gained for the direction of future work.

Cortical magnetic stimulation does not appear to have a prognostic value in complete SCI, whether in the paraplegic or quadriplegic patient. Reappearance of motor potentials in the upper limbs of some quadriplegic patients was seen after 6 months, so CMCT seems to parallel improvement but not predict it in these cases. In contrast, motor potentials were elicited in the acute phase in quadriplegic patients with an incomplete lesion who went on to make significant functional improvement, even though the latencies were prolonged. This 
Table III Change in central motor conduction time $(\mathrm{CMCT}-\mathrm{ms})$ and amplitude $(\mathrm{mV})$ measured during activation of muscle

\begin{tabular}{|c|c|c|c|c|c|c|c|c|c|c|c|c|c|c|c|c|c|c|c|c|c|}
\hline \multirow[t]{3}{*}{ Type } & \multirow{3}{*}{$\begin{array}{l}\text { Patient } \\
\text { number }\end{array}$} & \multirow{2}{*}{\multicolumn{2}{|c|}{$\begin{array}{l}\text { Assessment } \\
\text { time (days } \\
\text { from injury) }\end{array}$}} & \multicolumn{6}{|c|}{ Biceps brachii } & \multicolumn{6}{|c|}{ Abductor pollicis brevis } & \multicolumn{6}{|c|}{ Tibialis anterior } \\
\hline & & & & \multicolumn{3}{|c|}{ CMCT } & \multicolumn{3}{|c|}{ Amplitude } & \multicolumn{3}{|c|}{ СMCT } & \multicolumn{3}{|c|}{ Amplitude } & \multicolumn{3}{|c|}{ CMCT } & \multicolumn{3}{|c|}{ Amplitude } \\
\hline & & 1 st & $2 n d$ & $1 \mathrm{st}$ & 2nd & $2 n d-1 s t$ & 1st & 2nd & $2 \mathrm{nd}-1 \mathrm{st}$ & 1 st & $2 \mathrm{nd}$ & $2 n d-1 s t$ & 1 st & $2 n d$ & $2 \mathrm{nd}-1 \mathrm{st}$ & 1 st & 2 nd & $2 n d-1 s t$ & 1 st & 2 nd & 2 nd-1st \\
\hline \multirow{3}{*}{$\begin{array}{c}\text { Paraplegia } \\
\text { complete }\end{array}$} & 2 & 10 & 185 & 6.4 & 6.0 & -0.4 & 3.0 & 6.6 & +3.6 & 8.5 & 9.0 & +0.5 & 7.0 & 7.0 & () & NR & NR & - & NR & NR & - \\
\hline & 7 & 16 & 194 & 8.3 & 7.0 & -1.3 & 3.0 & 2.5 & -0.5 & 6.8 & 4.7 & -2.1 & 1.0 & 1.0 & () & NR & NR & - & NR & NR & - \\
\hline & 8 & 13 & 181 & 7.8 & 7.0 & -0.8 & 1.0 & 1.0 & ) & 12.7 & 12.1 & -0.6 & 1.0 & 1.5 & +0.5 & NR & NR & - & NR & NR & - \\
\hline \multirow{3}{*}{$\begin{array}{l}\text { Quadriplegia } \\
\text { incomplete }\end{array}$} & 3 & 8 & 190 & 7.0 & 7.1 & +0.1 & 8.0 & 6.0 & -2.0 & NR & NR & - & NR & NR & - & NR & NR & - & NR & NR & - \\
\hline & 6 & 13 & 206 & 4.5 & 6.2 & +1.7 & 1.8 & 4.0 & +2.2 & 10.8 & 10.6 & -0.2 & 0.1 & 3.0 & +2.9 & 19.0 & 10.5 & -8.5 & 0.5 & 0.7 & +0.2 \\
\hline & 10 & 8 & 195 & 14.2 & 13.9 & -0.3 & 0.2 & 0.5 & +0.3 & 11.8 & 6.6 & -5.2 & 1.0 & 1.0 & 0 & 22.32 & 20.1 & -2.2 & 1.0 & 1.0 & 0 \\
\hline \multirow{4}{*}{$\begin{array}{l}\text { Quadriplegia } \\
\text { complete }\end{array}$} & 1 & 5 & 180 & 6.1 & 10.0 & +3.9 & 0.7 & 0.5 & -0.2 & NR & NR & - & NR & NR & - & NR & NR & - & NR & NR & - \\
\hline & 4 & 5 & 182 & NR & 14.2 & - & NR & 0.4 & - & NR & 17.2 & - & NR & 0.3 & - & NR & NR & - & NR & NR & - \\
\hline & 5 & 43 & 197 & NR & 9.6 & - & NR & 1.0 & - & NR & NR & - & NR & NR & - & NR & NR & - & NR & NR & \\
\hline & 9 & 3 & 186 & NR & NR & - & NR & NR & - & NR & NR & - & NR & NR & - & NR & NR & - & NR & NR & - \\
\hline
\end{tabular}

$\mathrm{NR}=$ not recordable; $\mathrm{CMCT}$ upper limits of normal: $\mathrm{BB}=9.5 \mathrm{~ms}, \mathrm{APB}=9.2 \mathrm{~ms}, \mathrm{TA}=16.2 \mathrm{~ms}$; Amplitude lower limits of normal: $\mathrm{BB}=3 \mathrm{mV}$, $\mathrm{APB}=2 \mathrm{mV}, \mathrm{TA}=3 \mathrm{mV}$. 
suggests that motor evoked potentials may be able to refine the prognosis in patients with incomplete lesions. It remains to be seen whether the presence of motor evoked potentials is superior to clinical subdivision on the basis of the extent of the motor and sensory sparing. ${ }^{19}$

Studying motor potentials in the acute phase of spinal injury provides practical difficulties. Recruitment of patients was a major problem because of late referral from the primary admitting hospital. Also, rapid clinical deterioration in some quadriplegic patients necessitates transfer to the intensive care unit where studies cannot be undertaken. One patient (patient 5) was left in the trial having undergone clinical assessment before a respiratory arrest and hence the neurophysiological follow up assessments were delayed. Further studies of this sort will therefore require rapid transfer of SCI patients to specialist units. This is also to be encouraged to allow early treatment trials and/or steroid therapy. ${ }^{13}$ Further studies will also need to be multicentred to collect sufficient patients for subgroup analysis, particularly those with incomplete lesions subdivided by the 1992 Revised American Spinal Injury Association Classification. ${ }^{19}$

Animal studies have suggested that motor evoked potentials may be of some prognostic value. Using direct recordings of electrically elicited MEPs, it has been shown that weight-drop spinal cord injury in rats results in increased latency or loss of MEPs below the lesion. ${ }^{20,21}$ The recovery of the MEP mirrored clinical improvement in the animals. In similar studies in cats, ${ }^{22}$ MEPs recovered in some animals 24 hours before ambulation was regained suggesting that the test may have a prognostic role in SCI.

Previous studies have evaluated the prognostic value of the somatosensory evoked potential (SEP) following SCI. Whilst it has been suggested that the early preservation of SEPs correlates with a good neurological outcome, ${ }^{23}$ this has not been found by all workers. ${ }^{24-26}$

In conclusion, further multicentre studies should be developed to examine the prognostic ability of cortical magnetic stimulation in patients with incomplete lesions following spinal cord injury. It may be of more value in future studies to combine motor and sensory evoked potential studies to provide an overview of both motor and sensory function. Empirically this seems more likely to correlate with neurological improvement.

\section{Acknowledgements}

We are grateful to the patients and staff of the Spinal Injuries Unit of Pinderfields Hospital for their invaluable help in the study. We are also indebted to the technical staff of the Neurophysiology Department. We are grateful for the support of $\mathrm{Dr}$ Loizou, $\mathrm{Mr}$ Ahmed and $\mathrm{Mr}$ Tromans.

\section{References}

1 Merton PA, Morton HB (1980) Stimulation of the cerebral cortex in the intact human subject. Nature 285: 227-228.

2 Barker AT, Jalinous R, Freeston IL (1985) Non-invasive magnetic stimulation of human motor cortex. Lancet i: $1106-1107$.

3 Barker AT, Freeston IL, Jalinous R, Jarratt J (1986) Clinical evaluation of conduction time measurements in central motor pathways using magnetic stimulation of human brain. Lancet $\mathbf{i}: 1325-1326$.

4 Hess CW, Med D, Mills KR et al (1987) Magnetic brain stimulation: Central motor conduction studies in multiple sclerosis. Ann Neurol 22: 744-752.

5 Ingram DA, Thompson AJ, Swash M (1988) Central motor conduction in multiple sclerosis: Evaluation of abnormalities revealed by transcutaneous magnetic stimulation of the brain. $J$ Neurol Neurosurg Psychiatry 51: 487-494.

6 Eisen A, Shytbel W, Murphy K, Hoirch M (1990) Cortical magnetic stimulation in amyotrophic lateral sclerosis. Muscle Nerve 13: 146-151.

7 Schady W, Dick JPR (1991) Motor studies in hereditary spastic paraparesis. J Neurol Neurosurg Psychiatry 54: 775-779.

8 Claus D, Harding AE, Hess CW et al (1988) Central motor conduction in degenerative ataxic disorders: A magnetic stimulation study. J Neurol Neurosurg Psychiatry 51: 790-795.

9 Jaskolski DJ, Jarratt JA, Jakubowski J (1989) Clinical evaluation of magnetic stimulation in cervical spondylosis. Br J Neurosurg 3: 541-548. 
10 Noordhout AM, Remacle JM, Pepin JL et al (1991) Magnetic stimulation of the motor cortex in cervical spondylosis. Neurology 41: 75-80.

11 Dominikus M, Grisold W, Jelinek V (1990) Transcranial electrical motor evoked potentials as a prognostic indicator for motor recovery in stroke patients. J Neurol Neurosurg Psychiatry 53: 745-748.

12 Heald A, Bates D, Cartlidge NEF et al (1992) Comparison of electromagnetic stimulation of the brain and CT scans in predicting functional outcome after stroke. J Neurol Neurosurg Psychiatry 55: 418.

13 Bracken MB, Shepard MJ, Collins WF et al (1990) A randomized, controlled trial of methylprednisolone or naloxone in the treatment of acute spinal cord injury. $N$ Engl J Med 322: 1405-1411.

14 Thompson PD, Dick JPR, Asselman P et al (1987) Examination of motor function in lesions of the spinal cord by stimulation of the motor cortex. Ann Neurol 21: 389-396.

15 Giantusos J, Eberstein A, Ma D et al (1987) A non-invasive technique to assess completeness of spinal cord lesions in humans. Exp Neurol 98: 34-40.

16 Brouwer B, Bugaresti J, Ashby P (1992) Changes in corticospinal facilitation of lower limb spinal motor neurons after spinal cord lesions. J Neurol Neurosurg Psychiatry 55: 20-24.

17 Lissens MA, McKay WB, Dimitrijevic MR, van der Linden C (1992) Transcranial motor cortex stimulation in patients with established spinal cord injury. In: Lissens MA, editor. Clinical Applications of Magnetic Transcranial Stimulation. Uitgeverij Peeters, Leuven: 42-55.

18 Tegenthoff M (1992) Clinical applications of transcranial magnetic stimulation in acute spinal cord injury. In: Lissens MA, editor. Clinical Applications of Magnetic Transcranial Stimulation. Uitgeverij Peeters, Leuven: 33-41.

19 Young W (1992) Medical treatments of acute spinal cord injury. J Neurol Neurosurg Psychiatry 55: 635-639.

20 Fehlings MG, Tator CH, Linden RD, Piper IR (1987) Motor evoked potentials recorded from normal and spinal cord-injured rats. Neurosurgery 20: $125-130$.

21 Simpson RK, Baskin DS (1987) Corticomotor evoked potentials in acute and chronic blunt spinal injury in the rat: correlation with neurological outcome and histological damage. Neurosurgery 20: 131-137.

22 Levy WJ, McCaffrey M, Hagichi S (1987) Motor evoked potentials as a predictor of recovery in chronic spinal cord injury. Neurosurgery 20: 138-142.

23 Perot PL, Vera CL (1982) Scalp recorded somatosensory evoked potentials to stimulation of nerves in the lower extremities and evaluation of patients with spinal cord trauma. Ann N Y Acad Sci 388: 359-268.

24 York DH, Watts C, Raffensberger M et al (1983) Utilization of somatosensory evoked potentials in spinal cord injury. Prognostic limitations. Spine 8: 832-839.

25 McGarry J, Friedgood DL, Woolsey R et al (1984) Somatosensory evoked potentials in spinal cord injuries. Surg Neurol 22: 341-343.

26 Chabot R, York DH, Watts C, Waugh WA (1985) Somatosensory evoked potentials evaluated in normal subjects and spinal cord-injured patients. J Neurosurg 63: 544-551. 